$<$ Original Article $>$

\title{
High prevalence of Enterococcus spp. from dogs with otitis externa
}

\author{
Hyun-Jung $\mathrm{Jo}^{1 \dagger}{ }^{\dagger}$, Hee-Sun Chae ${ }^{2 \dagger}$, Hyun-Ju Kim ${ }^{1}$, Min-Ju Kim ${ }^{1}$, Gyu-Nam Park ${ }^{1}$, \\ Sang-Hun $\mathrm{Kim}^{1}$, Kyung-Soo Chang ${ }^{1 *}$ \\ ${ }^{1}$ Department of Clinical Laboratory Science, College of Health Sciences, Catholic University of Pusan, Busan 609-757, Korea \\ ${ }^{2}$ Seoul Metropolitan Government Research Institute of Public Health \& Environment, Gwacheon 427-070, Korea
}

(Received 23 March 2012; revised 28 May 2012; accepted 30 May 2012)

\section{Abstract}

Otitis externa (OE) is a frequent disease in the ear canals of dogs. To identify the pathogens causing $\mathrm{OE}$ in dogs and to determine their antimicrobial resistances, specimens were collected from animal hospitals in Daejeon. The isolates were examined by morphological and biochemical tests, 16S rRNA analysis and antimicrobial susceptibility tests. We analyzed correlation between the isolated pathogens and external factors of dogs such as breed, age, gender, ear mite, hair in ears and experience with antibiotic therapy. Thirty three strains of bacteria were isolated from 26 of the 68 heads of dogs with OE. The most isolated bacteria were Enterococcus faecalis (E. faecalis) followed by Staphylococcus aureus (Sta. aureus), Sta. pseudointermedius, E. faecium, E. avium and Streptococcus canis (Strep. canis) in order of frequency of occurrence. Isolation frequency of Enterococcus spp. and Staphylococcus spp. were $51.5 \%$ and $45.5 \%$, respectively. E. faecalis and E. faecium isolates showed VanB phenotype, which is resistant to vancomycin but sensitive to teicoplanin were $58 \%$ and $25 \%$, respectively. Nine isolates among total twelve isolates of E. faecalis were isolated from the dogs treated with antibiotics. There was no methicillin-resistant Sta. aureus (MRSA), but were MR-Sta. pseudointermedius (MRSP) (57.1\%) and vancomycin-resistant (VR)-Sta. pseudointermedius (14.3\%) (VRSP) showing VanB phenotype. However, vanA, vanB and $\operatorname{van} C$ genes were not detected in VR isolates from the dogs. Taken together, VR-Enterococcus spp. (VRE) is one of the major pathogens in domestic animals, as well as communityand hospital-acquired infection.

Key words : Dog, Otitis externa, Enterococcus spp., Antimicrobial resistance, van gene

\section{INTRODUCTION}

Otitis externa $(\mathrm{OE})$ is a frequent disease in the ear canal of a dog. Ear disease occupies $10 \sim 20 \%$ of dog disease and OE comprises 30\% of them (Angus, 2004; Eom et al, 2000). OE is an inflammation in the ear canal with a multifactorial etiology. Various combinations of the primary, predisposing, and perpetuating causes are interacting in occurrences of OE. Predisposing factors are ear conformation, excessive moisture and excessive cerumen production. Primary factors are micro-

*Corresponding author: Kyung-Soo Chang, Tel. +82-51-510-0565,

Fax. +82-51-510-0568, E-mail. kschang@cup.ac.kr

${ }^{\dagger}$ These authors contributed equally to this work. organisms, parasites, hypersensitivity diseases, keratinization disorders, autoimmune diseases and viral diseases. Frequent primary factors are allergenic dermatitis (43\%), grass awns $(12 \%)$ and ear mites $(7 \%)$ in order of frequency of occurrence in terms of etiology of $\mathrm{OE}$ (Lilenbaum et al, 2000; Saridomichelakis et al, 2007). Perpetuating factors are bacteria, yeast and progressive pathological changes (Rosser, 2004). Eventually, the perpetuating factors prevent effective healing of $\mathrm{OE}$. The most frequently isolated microorganism from dogs with $\mathrm{OE}$ is Staphylococcus pseudintermedius (Sta. pseudintermedius) (formerly referred to as Sta. intermedius), followed by Malassezia pachydermatis, Sta. aureus, Pseudomonas aeruginosa, Streptococcus canis (Strep. 
canis), Proteus mirabilis and Escherichia coli in order of frequency of occurrence (Lyskova et al, 2007; Oliveira et al, 2008; Zamankhan et al, 2010). Recently, antimicrobial resistances of these bacteria have been reported. Especially, some fluoroquinolone resistant bacteria are increasing (Oliveira et al, 2008; Yoo et al, 2010; Yoon et al, 2010). This might be due to excessive administering and unnecessary abuse. For this reason, there is no good response about $\mathrm{OE}$ treatment.

Enterococcus spp. is Gram-positive cocci and reclassified from Lancefield group D Streptococci. It is a normal flora in human intestines. In humans, isolation frequencies of Enterococcus faecalis (E. faecalis) and $E$. faecium are $90 \sim 95 \%$ and $5 \sim 10 \%$ each. E. casseliflavus, E. gallinarum and E. raffinosus have pathogenicity in animals (Kim et al, 2010a). These usually develop gastroenteritis in patients. It can be treated by ampicillin and vancomycin. Vancomycin is a glycopeptide antibiotic used to Gram-positive bacteria, and has been traditionally used after treatment with other antibiotics such as penicillin and methicillin had failed in clinics. Recently, vancomycin resistant bacteria have been increasing, and displaced by linezolid, daptomycin, and quinupristin/dalfopristin. Particularly, vancomycin-resistant Enterococcus spp. (VRE) has been trouble for hospital-acquired infection, and has to be treated with multiple antibiotic therapy due to multi-drug resistances (Kim et al, 2010a; Lai et al, 2011).

The purposes of this study were to identify the pathogens causing $\mathrm{OE}$ in dogs and to determine their antimicrobial resistances. Specimens were collected from the ears of dogs with $\mathrm{OE}$. The isolates were examined by morphological, biochemical tests, 16S rRNA analysis and antimicrobial susceptibility tests. In addition, we analyzed correlation between the isolated pathogens and external factors of dogs such as breed, age, gender, ear mite, hair in ears and experience with antibiotic therapy.

\section{MATERIALS AND METHODS}

\section{Samples}

Samples were collected from 68 dogs with OE hospi- talized at animal hospitals in Daejeon. The specimens were divided into several groups by external characteristics of dogs such as breed, age, gender, ear mite, hair in ears and experience with antibiotic therapy. The ear exudates of dogs were sampled with cotton swabs, stored to transport media, and transferred to laboratory to isolate bacterial pathogens from the samples.

\section{Bacterial isolation and identification}

Samples were cultured on 5\% sheep blood agar (SBA, Komed, Korea) and Sabouraud dextrose agar (SDA, Difco, USA) at $37^{\circ} \mathrm{C}$ for $18 \mathrm{hrs}$. Then, isolated bacteria and fungi were primarily classified by morphological characters such as Gram stain patterns and catalase and oxidase tests. Mannitol salt agar (MSA, Difco, USA), $\quad 0.04 \%$ tellurite BHI (BHI-tel) media and MacConkey agar (Mac, Difco, USA) were used as selective media for the isolation of Staphylococcus spp., Streptococcus spp. and Enterococcus spp., and Gram-negative bacilli such as $E$. coli, respectively. The cultures were carried out under aerobic and anaerobic conditions. The isolates were identified using API kits (BioMérieux, France) or Vitek system (BioMérieux, France). The identified bacteria were confirmed through a more accurate genotyping test based on nucleotide sequences of $16 \mathrm{~S}$ rRNA. For genotyping, the isolates were incubated in a brain-heart infusion broth (BHI-broth) at $37^{\circ} \mathrm{C}$ for 18 hrs. Their genomic DNAs were extracted using an Accuprep genomic DNA extraction kit (Bioneer, Korea). PCR using 16S rRNA primer sets was conducted as described previously (Kim et al, 2010b). After electrophoresis on agarose gels, individual amplified products were purified using an Accuprep gel purification kit (Bioneer, Korea). Then, the purified DNA was analyzed by DNA sequencing. The genotypes of the isolates were determined by BLAST analysis of the obtained base sequences. The sequences were identified through BLAST (http://www.ncbi.nlm.nih.gov) analysis. For analysis of van gene typing, PCR using van primer sets was conducted as described previously (Kim et al, 2010b). 


\section{Antimicrobial susceptibility}

The antimicrobial susceptibility test of the isolates was performed using Vitek GPS-450 and 451 kits (BioMérieux, France) for Gram-positive bacteria and Vitek GPS-433 and 434 kits (BioMérieux, France), or the disk diffusion method, for Gram-negative bacteria. The media used for antibiotic tests were Mueller Hinton agar or Blood agar and the disk diffusion method was conducted according to the Clinical Laboratory Standards Institute (CLSI, 2009) guidelines. The bacteria were dissolved into tryptic soy broth (TSB) and cultured for 1 $2 \mathrm{hrs}$ to make a bacterial suspension with a turbidity of MacFarland No. 0.5. The suspension was evenly smeared on Mueller Hinton agar using swabs and an antibiotic disk was placed on it. The bacteria were cultured for $18 \sim 24 \mathrm{hrs}$ at $37^{\circ} \mathrm{C}$ and their resistances to antibiotics were determined by measuring the diameter of the inhibition zone around the antibiotic disks. The isolation ratios of the isolates showing antibiotic resistance were statistically analyzed.

The selected antibiotics were clindamycin $(5 \mu \mathrm{g})$, erythromycin $(15 \mu \mathrm{g})$, linezolid $(30 \mu \mathrm{g})$, oxacillin $(1 \mu \mathrm{g})$, penicillin $(10 \mathrm{U})$, rifampicin $(5 \mu \mathrm{g})$, sulphamethoxazole-trimethoprim $(25 \mu \mathrm{g})$, teicoplanin $(30 \mu \mathrm{g})$, telithromycin $(15 \mu \mathrm{g})$, tetracycline $(30 \mu \mathrm{g})$, and vancomycin $(30 \mu \mathrm{g})$ for Staphylococcus spp., ampicillin $(10 \mu \mathrm{g})$, cefotaxime $(30 \mu \mathrm{g})$, chlorampenicol $(30 \mu \mathrm{g})$, ciprofloxacin $(5 \mu \mathrm{g})$, clindamycin $(2 \mu \mathrm{g})$, erythromycin $(15$ $\mu \mathrm{g})$, gentamicin $(10 \mu \mathrm{g})$, imipenem $(10 \mu \mathrm{g})$, linezolid $(30 \mu \mathrm{g})$, nitrofurantoin $(300 \mu \mathrm{g})$, penicillin $(10 \mathrm{U})$, quinupristin-dalfopristin $(15 \mu \mathrm{g})$, streptomycin $(10 \mu \mathrm{g})$, teicoplanin $(30 \mu \mathrm{g})$, tetracyclin $(30 \mu \mathrm{g})$, and vancomycin $(30 \mu \mathrm{g})$ for Streptococcus spp., and ampicillin $(10 \mu \mathrm{g})$, chlorampenicol $(30 \mu \mathrm{g})$, ciprofloxacin $(5 \mu \mathrm{g})$, gentamicin $(10 \mu \mathrm{g})$, imipenem $(10 \mu \mathrm{g})$, linezolid $(30 \mu \mathrm{g})$, nitrofurantoin $(300 \mu \mathrm{g})$, penicillin (10 $\mathrm{U})$, quinupristin-dalfopristin $(15 \mu \mathrm{g})$, streptomycin $(10 \mu \mathrm{g})$, teicoplanin (30 $\mu \mathrm{g})$, tetracyclin $(30 \mu \mathrm{g})$, and vancomycin $(30 \mu \mathrm{g})$, for Enterococcus spp.
Table 1. Isolation frequencies of pathogens isolated from dogs with otitis externa

\begin{tabular}{lcc}
\hline \multicolumn{1}{c}{ Genus } & $\begin{array}{c}\text { No. of isolated } \\
\text { species (\%) }\end{array}$ & $\begin{array}{c}\text { No. of isolated } \\
\text { genus (\%) }\end{array}$ \\
\hline $\begin{array}{l}\text { Enterococcus } \\
\text { E. faecalis }\end{array}$ & $17(51.5)$ \\
E. faecium & $12(36.4)$ & \\
E. avium & $4(12.1)$ & \\
Staphylococcus & $1(3.0)$ & $15(45.5)$ \\
Sta. aureus & & \\
Sta. pseudintermedius & $8(24.2)$ & $1(3.0)$ \\
Streptococcus & $7(21.2)$ & \\
$\quad$ Strep. canis & $1(3.0)$ & $33(100)$ \\
Total & $33(100)$ & \\
\hline
\end{tabular}

\section{RESULTS}

\section{Isolation frequency of pathogenic bacteria from the dogs}

Pathogenic bacteria were isolated from 26 of the 68 dogs. Thirty three bacterial stains were isolated from the dogs but no fungus. The most frequently isolated bacteria was E. faecalis (36.4\%), followed by Sta. aurues (24.2\%), Sta. pseudintermedius (21.2\%), E. faecium (12.1\%), E. avium (3.0\%) and Strep. canis (3.0\%) in order of frequency of occurrence. Enterococcus spp. (51.5\%) was a more isolated strain than Staphylococcus spp. (45.5\%). E. faecalis was the most isolated pathogen in Enterococcus spp. The isolation frequency of Sta. aureus and Sta. pseudintermedius was similar as shown in Table 1.

\section{Emergence of vancomycin-resistant pathogen}

Almost all of E. faecalis isolates were resistant to gentamicin, quinupristin-dalfopristin and streptomycin, and were resistant to penicillin but sensitive to imipenem, nitrofurantoin and teicoplanin. Likewise, most $E$. faecium isolates were resistant to ampicillin and tetracycline, and were sensitive to imipenem, nitrofurantoin and teicoplanin like those of E. faecalis isolates. E. faecalis and E. faecium isolates showed VanB phenotype which is resistant to vancomycin but sensitive to teicoplanin were $58 \%$ and $25 \%$, respectively (Table 2 ), (Kim et al, 2010b). All of Staphylococcus spp. isolates were 
Table 2. Antimicrobial resistance patterns of the Enterococcus spp. isolates

\begin{tabular}{lcc}
\hline \multicolumn{1}{c}{ Antimicrobial drugs } & E. faecalis & E.faecium \\
\hline Ampicillin & $3 / 12^{*}$ & $4 / 4$ \\
Chlorampenicol & $4 / 12$ & $1 / 4$ \\
Ciprofloxacin & $1 / 12$ & $1 / 4$ \\
Gentamicin & $12 / 12$ & $3 / 4$ \\
Imipenem & $0 / 12$ & $0 / 4$ \\
Linezolid & $6 / 12$ & $3 / 4$ \\
Nitrofurantoin & $0 / 12$ & $0 / 4$ \\
Penicillin & $12 / 12$ & $3 / 4$ \\
Quinupristin-Dalfopristin & $12 / 12$ & $3 / 4$ \\
Streptomycin & $12 / 12$ & $3 / 4$ \\
Teicoplanin & $0 / 12$ & $0 / 4$ \\
Tetracyclin & $11 / 12$ & $4 / 4$ \\
Vancomycin & $7 / 12$ & $1 / 4$ \\
\hline
\end{tabular}

*Numbers of the isolates showing antimicrobial resistance/numbers of the total isolates.

Table 3. Antimicrobial resistance patterns of the Staphylococcus spp. isolates

\begin{tabular}{lcc}
\hline \multicolumn{1}{c}{ Antimicrobial drugs } & Sta. aureus & Sta. pseudintermedius \\
\hline Clindamycin & $2 / 8^{*}$ & $4 / 7$ \\
Erythromycin & $2 / 8$ & $4 / 7$ \\
Linezolid & $0 / 8$ & $0 / 7$ \\
Oxacillin & $0 / 8$ & $4 / 7$ \\
Penicillin & $0 / 8$ & $0 / 7$ \\
Rifampicin & $1 / 8$ & $0 / 7$ \\
Sulphamethoxazole- & $4 / 8$ & $4 / 7$ \\
$\quad$ Trimethoprim & & \\
Teicoplanin & $0 / 8$ & $0 / 7$ \\
Telithromycin & $2 / 8$ & $4 / 7$ \\
Tetracycline & $6 / 8$ & $7 / 7$ \\
Vancomycin & $0 / 8$ & $1 / 7$ \\
\hline
\end{tabular}

*Numbers of the isolates showing antimicrobial resistance/numbers of the total isolates.

sensitive to almost all of antibiotics, especially antibiotics that inhibit synthesis of cell walls. Susceptibilities of Sta. aureus isolates were higher than those of Sta. pseudintermedius. Sta. pseudintermedius isolates were resistant to tetracycline. There was no methicillin-resistant Sta. aureus (MRSA) isolates but were MR-Sta. pseudointermedius isolates (57.1\%). Moreover, one strains of vancomycin-resistant (VR)-Sta. pseudointermedius (VRSP) (14.3\%) showing VanB phenotype were isolated (Table 3). However, vanA, vanB, and vanC genes were not detected in VR isolates of both Enterococcus spp. and Staphylococcus spp. The anti-
Table 4. Antimicrobial resistance patterns of the E. avium and Strep. canis spp. isolates

\begin{tabular}{lcc}
\hline \multicolumn{1}{c}{ Antimicrobial drugs } & E. avium & Strep. canis \\
\hline Ampicillin & $\mathrm{S}^{*}$ & $\mathrm{R}$ \\
Chlorampenicol & $\mathrm{S}$ & $\mathrm{R}$ \\
Ciprofloxacin & $\mathrm{S}$ & $\mathrm{I}$ \\
Gentamicin & $\mathrm{S}$ & $\mathrm{S}$ \\
Imipenem & $\mathrm{S}$ & $\mathrm{S}$ \\
Linezolid & $\mathrm{S}$ & $\mathrm{R}$ \\
Nitrofurantoin & $\mathrm{S}$ & $\mathrm{S}$ \\
Penicillin & $\mathrm{S}$ & $\mathrm{R}$ \\
Quinupristin-Dalfopristin & $\mathrm{R}^{\dagger}$ & $\mathrm{S}$ \\
Streptomycin & $\mathrm{S}$ & $\mathrm{S}$ \\
Teicoplanin & $\mathrm{I}^{\ddagger}$ & $\mathrm{S}$ \\
Tetracyclin & $\mathrm{R}$ & $\mathrm{R}$ \\
Vancomycin & $\mathrm{S}$ & $\mathrm{S}$ \\
Cefotaxine & - & $\mathrm{S}$ \\
Clindamycin & - & $\mathrm{S}$ \\
Erythromycin & - & $\mathrm{S}$ \\
\hline
\end{tabular}

${ }^{*}$ Susceptibility, ${ }^{\dagger}$ Resistance, ${ }^{\ddagger}$ Intermediate.

Table 5. Comparison of isolation frequencies of pathogens from the dogs with or without antibiotic therapy

\begin{tabular}{lllc}
\hline \multicolumn{1}{c}{ Species } & $\begin{array}{c}\text { Treated } \\
\text { group }\end{array}$ & $\begin{array}{c}\text { Non-Treated } \\
\text { group }\end{array}$ & Total \\
\hline E. faecalis & $9(27.3)^{*}$ & $3(9.1)$ & $12(36.4)$ \\
E. faecium & $0(0)$ & $4(12.1)$ & $4(12.1)$ \\
E. avium & $1(3.0)$ & $0(0)$ & $1(3.0)$ \\
Sta. aureus & $4(12.1)$ & $4(12.1)$ & $8(24.2)$ \\
Sta. pseudintermedius & $3(9.1)$ & $4(12.1)$ & $7(21.2)$ \\
Strep. canis & $0(0)$ & $1(3.0)$ & $1(3.0)$ \\
Total & $17(51.5)$ & $16(48.5)$ & $33(100)$ \\
\hline
\end{tabular}

*Numbers of the isolates (\%).

microbial susceptibility patterns of E. avium and Strep. canis isolates are shown in Table 4. E. avium was susceptible to vancomycin and teicoplanin. Therefore, 8 isolates (47.1\%) among total 17 Enterococcus spp. isolates showed VanB phenotype without van gene.

\section{High frequency of $E$. faecalis in dogs treated with antibiotics}

In comparing the relationship between the frequency of specific pathogenic bacteria and external factors of dogs such as breed, age, gender, ear mite, hair in ears and experience with antibiotic therapy, 9 isolates (75\%) among 12 isolates of E. faecalis were isolated in the 
Table 6. Comparison of isolation frequencies of pathogens from the dogs by age

\begin{tabular}{lccc}
\hline \multicolumn{1}{c}{ Species } & Over 1 year & Under 1 year & Total \\
\hline E. faecalis & $11^{*}(33.3)$ & $1(3.0)$ & $12(36.4)$ \\
E. faecium & $0(0)$ & $4(12.1)$ & $4(12.1)$ \\
E. avium & $1(3.0)$ & $0(0)$ & $1(3.0)$ \\
Sta. aureus & $4(12.1)$ & $4(12.1)$ & $8(24.2)$ \\
Sta. pseudintermedius & $3(9.1)$ & $4(12.1)$ & $7(21.2)$ \\
Strep. canis & $0(0)$ & $1(3.0)$ & $1(3.0)$ \\
Total & $19(57.6)$ & $14(42.4)$ & $33(100)$ \\
\hline
\end{tabular}

*Numbers of the isolates (\%).

dogs treated with antibiotics. In contrast, all isolates of E. faecium were isolated in non-treated group (Table 5). Most of E. faecalis isolates were isolated from the over 1-year-old dogs (91.7\%), but all E. faecium isolates were isolated from the under 1-year-old group (Table 6). There was no relationship between the external characteristics except for experience with antibiotic therapy and age (Table 7).

\section{DISCUSSION}

A dog is a companion animal and is a part of a number of families. When a dog is infected with microorganisms, the dog can become a carrier to infect a human. We isolated numbers of Enterococcus spp. $(51.5 \%)$, which is a major pathogen in community and hospital-acquired infection. This is the first report studying Enterococcus spp. isolated from dogs with $\mathrm{OE}$ in Korea (Lyskova et al, 2007; Oliveira et al, 2008; Zamankhan et al, 2010). There are some studies referring Enterococcus spp. isolated from OE. Brothers et al (2002) isolated one Enterococcus spp. from OE. Nevertheless, they did not identify an exact species. De Graef et al (2001) isolated two Enterococcus spp. and identified them as E. faecium at first. After DNA analysis, those were conformed as Enterococcus canis. Hariharan et al (2006) isolated 9 E. faecalis among 44 Enterococcus spp. They suggested that increase of antibiotic resistance of Enterococcus spp. resulted from the treatment of otitis caused by Staphylococcus spp. However, they focused at Staphylococcus spp. and Pseudomonas spp.. We isolated 12 E. faecalis and 4 E.
Table 7. Comparison of isolation frequencies of pathogens from the dogs by external factor of dog

\begin{tabular}{lccc}
\hline \multicolumn{1}{c}{ Species } & Male & Ear mite & Hair in ears \\
\hline E. faecalis & $5 / 12^{*}$ & $3 / 12$ & $4 / 12$ \\
E. faecium & $3 / 4$ & $3 / 4$ & $3 / 4$ \\
E. avium & $1 / 1$ & $1 / 1$ & $0 / 1$ \\
Sta. aureus & $5 / 8$ & $4 / 8$ & $5 / 8$ \\
Sta. pseudintermedius & $4 / 7$ & $3 / 7$ & $3 / 7$ \\
Strep. canis & $1 / 1$ & $1 / 1$ & $1 / 1$ \\
\hline
\end{tabular}

*Numbers of the positive isolates/numbers of the total isolates.

faecium to cause pathogenicity to human. This result suggests that natural acquired VRE without van gene has been increasing and is one of serious problems in public health.

Most of Enterococcus spp. isolates were E. faecalis. The E. faecalis were isolated from dogs over 1 year old. All E. faecium were isolated from dogs under 1 year old (Table 6). However, more information is needed to elucidate correlation with disease occurrence by each Enterococcus spp. and age of dog. In addition, $E$. faecalis are mostly isolated in dogs treated with antibiotics $(75 \%)$. This suggests that appropriate treatment is not conducive to healing dogs with OE.

Occurrence of OE by Enterococcus spp. has not been fully understood. There are some reports about E. faecalis prevalence isolated from feces of other animals such as chickens and pigs (Hwang et al, 2011; Zou et al, 2011). Among the isolated Enterococcus spp., the isolation rate of VRE showing VanB phenotype was 47.1\% in this study. High frequency of VRE isolates is a serious problem in public health as well as human and animal diseases (Vincze et al, 2010). Isolation frequency of Staphylococcus spp. was still high though is lower than that of Enterococcus spp. There was no MRSA but was MR-Sta. pseudintermedius (MRSP), which showed multidrug resistance (MDRSP). The increase of MRSP or MDRSP causes an increase of OE in a dog. Moreover, VRSP was isolated in this study. Recently, emergence of coagulase-negative Staphylococcus spp. (CNS) such as Sta. pseudintermedius, and MRCNS or MDCNS has been increasing and is a serious problem in humans and animals (Lilenbaum et al, 2000; Yoo et al, 2010; Yoon et al, 2010).

Although OE by fungi has still been occurring, patho- 
genic fungi were not isolated from the samples in this study. To reduce the antibiotic resistance, prohibition of excessive administering and unnecessary abuse is required.

\section{ACKNOWLEDGMENTS}

This study was supported by the research fund from Catholic University of Pusan (CUP), Republic of Korea in 2011.

\section{REFERENCES}

Angus JC. 2004. Otic cytology in health and disease. Vet Clin North Am Small Anim Pract 34: 411-424.

Brothers AM, Gibbs PS, Wooley RE. 2002. Development of resistant bacteria isolated from dogs with otitis externa or urinary tract infections after exposure to enrofloxacin in vitro. Vet Ther 3: 493-500.

Cliniccal and Laboratory Standard Institute. 2009. Performance standards for antimicrobial disk susceptibility test, Approved standard, 10th ed. CLSI document M02-A10. Wayne, Pennsylvania.

De Graef EM, Devriese LA, Vancanneyt M, Baele M, Collins MD, Lefebvre K, Swings J, Haesebrouck F. 2003. Description of Enterococcus canis sp. nov. from dogs and reclassification of Enterococcus porcinus Teixeira et al. 2001 as a junior synonym of Enterococcus villorum Vancanneyt et al 2001. Int J Syst Evol Microbiol 53: 1069-1074.

Eom K, Lee H, Yoon J. 2000. Canalographic evaluation of the external ear canal in dogs. Vet Radiol Ultrasound 41: 231-234.

Hariharan H, Coles M, Poole D, Lund L, Page R. 2006. Update on antimicrobial susceptibilities of bacterial isolates from canine and feline otitis externa. Can Vet J 47: 253-255.

Kim HJ, Kwon HY, Kim KL, Lee HJ, Jo HJ, Hwang SM, Chang KS. 2010a. Characterization of vancomycin-resistant enterococci isolated from stools and their acquisition of vancomycin resistance. J Bacteriol Virol 40: 179-189.

Kim LJS, Lee HO, Kim HJ, Chang KS. 2010b. Isolation frequency and antimicrobial susceptibility of bacterial pathogens isolated from physical therapeutic instruments in general hospitals. J Phys Ther Sci 22: 61-67.

Hwang IY, Lim SK, Ku HO, Park CK, Jung SC, Park YH, Nam HM. 2011. Occurrence of virulence determinants in fecal Enterococcus faecalis isolated from pigs and chickens in Korea. J Microbiol Biotechnol 21: 1352-1355.

Lai CC, Wang CY, Chu CC, Tan CK, Lu CL, Lee YL, Huang YT, Lee PI, Hsueh PR. 2011. Correlation between antimicrobial consumption and resistance among Staphylococcus aureus and enterococci causing healthcare-associated infections at a university hospital in Taiwan from 2000 to 2009. Eur J Clin Microbiol Infect Dis 30: 265-271.

Lilenbaum W, Veras M, Blum E, Souza GN. 2000. Antimicrobial susceptibility of staphylococci isolated from otitis externa in dogs. Lett Appl Microbiol 31: 42-45.

Lyskova P, Vydrzalova M, Mazurova J. 2007. Identification and antimicrobial susceptibility of bacteria and yeasts isolated from healthy dogs and dogs with otitis externa. J Vet Med A Physiol Pathol Clin Med 54: 559-563.

Oliveira LC, Leite CA, Brilhante RS, Carvalho CB. 2008. Comparative study of the microbial profile from bilateral canine otitis externa. Can Vet J 49: 785-788.

Rosser EJ Jr. 2004. Causes of otitis externa. Vet Clin North Am Small Anim Pract 34: 459-468.

Saridomichelakis MN, Farmaki R, Leontides LS, Koutinas AF. 2007. Aetiology of canine otitis externa: a retrospective study of 100 cases. Vet Dermatol 18: 341-347.

Vincze S, Paasch A, Walther B, Ruscher C, Lübke-Becker A, Wieler LH, Barbara K. 2010. Multidrug- and methicillin resistant Staphylococcus pseudintermedius as a cause of canine pyoderma: a case report. Berl Munch Tierarztl Wochenschr 123: 353-358.

Yoo JH, Yoon JW, Lee SY, Park HM. 2010. High prevalence of fluoroquinolone- and methicillin-resistant Staphylococcus pseudintermedius isolates from canine pyoderma and otitis externa in veterinary teaching hospital. $\mathrm{J}$ Microbiol Biotechnol 20: 798-802.

Yoon JW, Lee KJ, Lee SY, Chae MJ, Park JK, Yoo JH, Park HM. 2010. Antibiotic resistance profiles of Staphylococcus pseudintermedius isolates from canine patients in Korea. J Microbiol Biotechnol 20: 1764-1768.

Zamankhan Malayeri H, Jamshidi S, Zahraei Salehi T. 2010. Identification and antimicrobial susceptibility patterns of bacteria causing otitis externa in dogs. Vet Res Commun 34: $435-444$.

Zou LK, Wang HN, Zeng B, Li JN, Li XT, Zhang AY, Zhou YS, Yang X, Xu CW, Xia QQ. 2011. Erythromycin resistance and virulence genes in Enterococcus faecalis from swine in China. New Microbiol 34: 73-80. 